\title{
As performances da rádio Xibé e a metáfora do espectro
}

\section{Resumo}

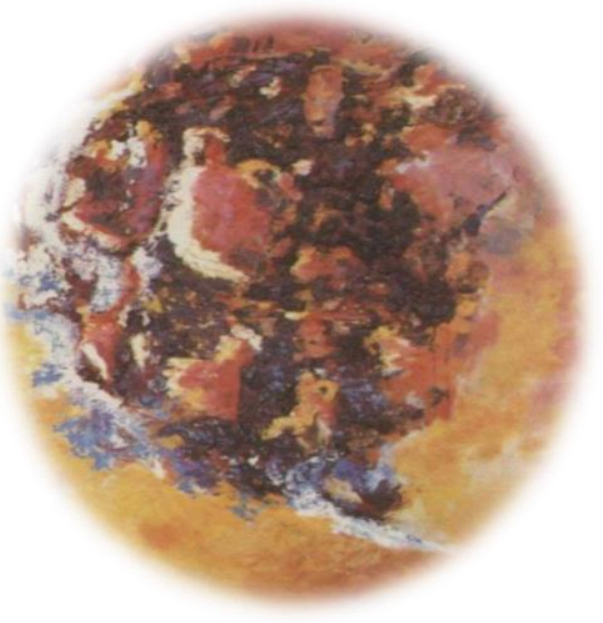

Resumo crítico sobre a tese "Inventando autonomias no Médio Solimões: uma etnografia dialógica da rádio Xibé e suas redes", defendida no Museu Nacional da UFRJ em 2015. Aborda a trajetória do pesquisador, a formulação de uma antropologia dialógica da mídia inspirada nas teorias pós-coloniais e na antropologia do colonialismo, a elaboração de um conceito de performance que ajuda a pensar a resistência nas práticas e narrativas dos participantes da rádio Xibé, a tecedura de uma narrativa polifônica da história da Xibé, a etnografia virtual das relações e percepções sobre a rádio por parte de militantes que interagiram com ela à distância pela internet, e a revisão crítica da história do rádio e da sua importância nas lutas contemporâneas por autonomia.

Palavras-chave: Rádio livre. Autonomia. Internet. Rede. Performance. Amazônia.

Em 20 de fevereiro de 2015 defendi a tese de doutorado "Inventando autonomias no Médio Solimões: uma etnografia dialógica da rádio Xibé e suas redes" no PPG em Antropologia Social do Museu Nacional da UFRJ. Este trabalho é um resumo crítico ${ }^{2}$ da pesquisa, cujo objetivo foi etnografar

1 Professor do Programa de Pós-Graduação Interdisciplinar em Ciências Humanas e do Curso dePedagogia do Centro de Estudos Superiores de Tefé da Universidade do Estado do Amazonas.

2 Por resumo crítico entendo uma reflexão sobre a obra e não mera síntese. 
a experiência dos participantes da rádio Xibé em Tefé (Amazonas, Brasil) desde 2004, quando surgiu o primeiro coletivo de rádio livre na cidade. Passa por 2006, quando começou o Centro de Mídia Independente de Tefé (CMITefé) que deu início às transmissões da rádio Xibé no campus da Universidade do Estado do Amazonas e em oficinas realizadas em bairros, escolas, comunidades e aldeias. A tese segue até 2007, quando a rádio perdeu o espaço que tinha na universidade, mas acentuou o seu envolvimento com movimentos sociais para a realização de oficinas. Além disso, foi feita a etnografia virtual dos movimentos em rede nos quais a Xibé se conecta usando a internet. O maior desafio foi tecer uma história polifônica, a partir das diferentes perspectivas dos participantes da rádio e das redes a que ela esteve conectada. Como o facilitador da tese também é participante da rádio, a etnografia está enraizada em sua trajetória.

\section{Trajetória do pesquisador}

De 1996 a 2006 foi pesquisado o mexicano Exército Zapatista de Libertação Nacional (EZLN) através de iniciação científica e mestrado na Universidade de Campinas (Unicamp), e do Programa de Formação de Quadros Profissionais do Centro Brasileiro de Análise e Planejamento (CEBRAP). A pesquisa de campo ocorreu no final de 1998 e começo de 1999, e a defesa foi em 2003. O interesse no EZLN ocorreu por sua capacidade de inventar mecanismos de participação política para a construção da autonomia local e de um movimento global anticapitalista, mas a pesquisa revelou que a comunicação dialógica é que está no âmago de sua luta. Isso inspirou a entrada do pesquisador no movimento de rádios livres em 1999, inicialmente na rádio Muda de Campinas (São Paulo, Brasil), onde passou a atuar principalmente na experimentação de novas linguagens artísticas e radiofônicas.

Em 2004 surgiu a oportunidade de mudança para Tefé, onde o ativista projetou (Todorov, 1999) a visão romântica de que seria um lugar 
recuado no tempo da exploração, menos capitalista e com um potencial de resistência semelhante ao da terra dos zapatistas mexicanos. Ao chegar no interior do Amazonas para trabalhar, o ativista ajudou a começar o coletivo Curupira de rádio livre, numa situação em que já havia outras experiências de comunicação alternativa sendo facilitadas pela Igreja Católica, o Instituto de Desenvolvimento Sustentável Mamirauá (IDSM) e a juventude skatista e rockeira. Dessas experiências anteriores vieram sujeitos importantes para a história da rádio livre Xibé.

\section{Partindo de categorias ao mesmo tempo teóricas e nativas}

O movimento de rádios livres sempre contou com a participação de intelectuais, entre eles Félix Guattari, que ajudou a divulgar o movimento em vários países. Entre 1979 e 1992 (pouco antes de falecer) ele esteve no Brasil sete vezes e, em 1986, escreveu o prefácio para a obra "Rádios livres: reforma agrária no ar", de Arlindo Machado, Caio Magri e Marcelo Masagão, militantes da rádio livre Xilik da PUC-SP e pioneiros do movimento no Brasil. Gilles Deleuze e Guattari (1995), e o movimento autonomista dos anos 1970 e 1980 na Europa deixaram conceitos importantes para o atual movimento de rádios livres ${ }^{3}$, tais como "desejo" e "rizoma". A ideia de comunicação dialógica defendida por Guattari era mais antiga, remetendo

\footnotetext{
${ }^{3}$ Nos anos 1980 não era comum no Brasil o nome "rádio comunitária", e as várias correntes de luta pela democratização do rádio usavam a expressão "rádio livre". Como ela passou a incluir inúmeras rádios clandestinas comerciais e de proselitismo partidário ou religioso, o conceito de "comunitária" foi introduzido por grupos que pretendiam uma distinção mais clara das experiências com compromisso democrático e popular, e que lutavam por sua legalização. Foi criada a lei $\mathrm{n}^{\circ}$ 9.612/1998 das rádios comunitárias e, com o tempo, esta expressão também se banalizou. Nunca deixou de existir, porém, um movimento de rádios livres que se manteve fiel às ideias e práticas libertárias inspiradas na experiência da rádio Alice da Itália dos anos 1970, e que foram internacionalmente divulgadas por Guattari. Após o levante zapatista de 1994 esse movimento iniciou uma nova fase de expansão em vários países, inclusive no Brasil.
} 
aos marxistas Walter Benjamin (1994), Bertolt Brecht (2007) e Hans Magnus Enzensberguer (2003). Como participante e pesquisador do movimento de rádios livres, era inevitável que o facilitador da tese partisse dessas categorias ao mesmo tempo nativas e teóricas. Isso trouxe uma dupla dificuldade: se já é difícil para um pesquisador nativo se distanciar das categorias que utiliza em sua vida cotidiana, o desafio pode ser maior quando as teorias que usa na pesquisa também são nativas. Afinal, as teorias podem ser um instrumento precioso de distanciamento. Assim, foi necessário um esforço dobrado de desnaturalização do ponto de vista do pesquisador, e duas estratégias contribuíram para este objetivo.

A primeira foi a proposta de uma antropologia dialógica da mídia. $\mathrm{O}$ campo da antropologia da mídia começou a se consolidar internacionalmente no começo dos anos 2000, quando foram publicadas diversas coletânea. Em 2003 foi publicada a obra "Antropologia e Comunicação" de Isabel Travancas e Patrícia Farias, mas o campo tem encontrado dificuldade para se consolidar no Brasil porque os mecanismos da carreira acadêmica levam os seus pesquisadores a migrar para outros campos de pesquisa já estabelecidos (Isabel Travancas. Entrevista pessoal Nº1. Outubro de 2014). Uma das riquezas da antropologia da mídia é o hibridismo, pois para ela são levadas as diferentes tradições teóricas da antropologia e de áreas afins, tais como os estudos culturais e os estudos de comunicação. A antropologia dialógica da mídia consiste em levar para este campo a contribuição da antropologia do colonialismo e demais teorias pós-coloniais, das quais o pesquisador se aproximou por influência da luta zapatista e do curso de doutorado.

Gayatri Spivak (2012) ajudou na elaboração do primeiro distanciamento importante em relação ao pensamento de Deleuze e Guattari. A autora demonstra que o pensamento desses autores impede a utilização de conceitos de origem marxista como "ideologia" e "interesse", pois formulam uma teoria do desejo imanente na qual parece que os sujeitos sempre podem 
se expressar. A autora afirma que, nas relações de dominação, a ideologia dominante fornece molduras com as quais o subalterno precisa lidar para conseguir se fazer ouvir. Um exemplo cruel é a situação das mulheres indianas, que encontram-se no meio do fogo cruzado entre a tradição patriarcal e um colonialismo que usa ideias feministas para atestar a superioridade moral do Ocidente: se elas criticam o machismo em sua sociedade acabam por se tornar úteis aos "homens brancos salvando mulheres de pele escura de homens de pele escura" (p. 122), e se atacam o colonialismo suas ideias podem ser capturadas para se reforçar o machismo das tradições. Como escapar a este impasse? Spivak (2012) utiliza Derridá para afirmar que, para permitir a expressão do outro, é preciso fazer delirar o outro que existe dentro de nós. Quanto ao sujeito que procura se expressar, a tática mais bem sucedida é a expressão que joga com as ambiguidades, operando deslocamentos de sentido e dificultando o enquadramento pelas molduras dominantes. A autora dá o exemplo de Bhuvaneswari, uma adolescente com 16 ou 17 anos que enforcou-se em 1926 em Calcutá. Ela fazia parte da luta armada pela independência, e recebeu a missão de cometer um assassinato político. Como não foi capaz de realizar a tarefa, mas não queria trair a confiança nela depositada, se matou. $\mathrm{Na}$ época os suicídios femininos eram entendidos como casos de gravidez ilícita, então a jovem esperou chegar a sua menstruação para se matar: a jovem conseguiu produzir efeitos de perplexidade, que tornaram possível as interpretações do seu ato para além das ideologias dominantes. O que se reteve para a tese foi a necessidade de se trabalhar a tensão entre a expressão dos sujeitos e as ideologias dominantes.

Frantz Fanon (2005) foi importante para a análise da trajetória do pesquisador e para a conversão dela em método de luta, educação e pesquisa através do conceito de "escola do povo". O autor afirma que a burguesia das colônias africanas se desenvolveu não por esforço próprio, mas servindo às burguesias metropolitanas, e por isso imita o seu pensamento. No começo 
da luta de libertação nacional, esta burguesia apoiou o diálogo com as metrópoles. Quando a independência foi conquistada, formou regimes autoritários, policiais, apoiando-se em líderes populistas e partidos sem participação popular. Os seus intelectuais, formados na cultura metropolitana, eram incapazes de dialogar com o povo e faziam da erudição um instrumento de poder e a prova de que as massas deviam ser dirigidas. Porém, durante a guerra de libertação nacional uma parte desses intelectuais precisou fugir da repressão e se refugiar nas comunidades camponesas. Ali aprendeu a dialogar com o povo ao participar das suas lutas, e perdeu o interesse na cultura ocidental que pouco tinha a contribuir com "o combate concreto no qual o povo se engajou" (p. 64). Surge assim o conceito de "escola do povo": nas assembleias do movimento popular os intelectuais aprendiam a cultura popular e ensinavam os seus saberes eruditos, e era o diálogo voltado à ação que se encarregava de filtrar e resignificar esses saberes na produção da "cultura nacional".

A cultura para a qual se inclina o intelectual é, muitas vezes, apenas um estoque de particularismos. Querendo colar-se ao povo, cola-se ao revestimento visível. Ora, esse revestimento é somente um reflexo de uma vida subterrânea, densa, em perpétua renovação. Essa objetividade que entra pelos olhos e que parece caracterizar o povo, é apenas, na verdade, o resultado inerte e já negado de adaptações múltiplas e nem sempre coerentes de uma substância mais fundamental que, esta sim, está em plena renovação (FANON, 2005, p. 257).

A analogia da escola do povo com a trajetória do pesquisador devese ao fato de que a sua mudança para viver em Tefé ocorreu inspirada no exemplo do EZLN, que foi formado inicialmente por jovens urbanos que se mudaram para a Selva Lacandona para formar um foco guerrilheiro. As narrativas da guerrilha afirmam que a intenção era recrutar camponeses para a luta armada, mas aconteceu o contrário: foram os povos indígenas que converteram os militantes da cidade para a sua cultura e as suas lutas. Através do conceito de escola do povo de Fanon (2005) foi possível iniciar a 
transformação do engajamento do facilitador em ingrediente importante da metodologia de pesquisa e vice versa.

A construção de uma metodologia dialógica teve continuidade principalmente com a obra de Johannes Fabian. Em um texto de 1971, Fabian (1996) defendeu a ideia de que o que fundamenta a produção do conhecimento não é a teoria ou a coleta consistente de dados, mas o diálogo intersubjetivo. Fabian (1983) afirma que a temporalidade presente nas ciências humanas ocidentais é marcada pela reprodução da ideia bíblica do tempo enquanto sequência de eventos que acontecem com o "povo escolhido". Daí surgiram as teorias da história lineares e divididas em fases, nas quais os povos ocidentais figuram como os mais evoluídos. Embora a antropologia tenha nascido da crítica de algumas formas do pensamento evolucionista e se empenhado em metodologias de pesquisa sincrônicas, ela reproduz essa temporalidade bíblica quando transforma as fases da história linear na distribuição no espaço de povos que pertencem a temporalidades diferentes. A dicotomia entre a temporalidade do pesquisador, que se considera membro de uma cultura mais complexa, e a dos seus interlocutores, a quem atribui um caráter primitivo ou menos evoluído, limita perigosamente a capacidade de diálogo na produção antropológica. Segundo Fabian $(1983 ; 2001)$ as viagens etnográficas propiciam diálogos fecundos, mas estes acabam subordinados ao debate entre pesquisadores ocidentais que acontece na análise e na produção teórica. É necessário, portanto, desconstruir a defasagem temporal entre o pesquisador e seus interlocutores, bem como criar técnicas para que estes participem da análise e da produção teórica. Além disso, é necessário que as condições concretas em que acontece o diálogo sejam objeto de descrições e análise crítica (Fabian, 2008).

A segunda estratégia para desnaturalizar a perspectiva do pesquisador foi desenvolver os conceitos de "performance" e "estilo". Essa abordagem teve início em 2004, quando começou a utilizar a obra de Michel de Certeau 
(2003) inspirado no Festival Mídia Tática ${ }^{4}$, que teve o seu nome inspirado no conceito de "tática" do autor. O termo era uma das inúmeras expressões usadas pelo autor para se referir às "artes de fazer", "invenção", "bricolagem", "apropriação", "resistência", "cultura popular", etc, práticas pelas quais os subalternos da sociedade industrial inventam novos usos para as tecnologias produzidas pela sociedade dominante, a partir de seus interesses e tradições. Inicialmente este conceito foi muito útil nas pesquisas sobre Tefé pois, além de valorizar a criatividade como forma de resistência (algo também enfatizado pelos zapatistas), ajudava a pensar a transformação social em uma região onde não há movimentos sociais grandes e famosos. Surgiu o interesse pelas formas de resistência existentes na vida cotidiana, ponto de partida necessário para a invenção de formas mais elaboradas de luta. Um amadurecimento importante desta abordagem se deu a partir da leitura da crítica de Lila Abu-Lughod (1990) que, de modo análogo a Spivak (2012), criticou o romantismo dos estudos sobre resistência por acabarem silenciando sobre as relações de poder nas quais as resistências se colocam. A partir da leitura de Foucault, a autora afirma que há uma relação estreita entre as formas de resistência e de dominação, e por isso uma ajuda a revelar a outra.

A partir desta crítica, as obras de James Ferguson (1999), Judith Butler (2012), Richard Bauman e Charles Briggs (1990), e João Pacheco de Oliveira (2008; 2009; 2010; 2014) foram referências para se elaborar o conceito de performance que é invenção singular atravessada por estilos em diferentes intensidades. Como afirma Butler (2012), as performances são feitas de repetição e criação, sendo que é através desta última que os estilos impostos pela sociedade são desnaturalizados, abrindo-se caminhos para transformações nas relações de gênero. Ferguson (1999) reelabora esses

4 O Mídia Tática foi um festival que reunia inúmeras experiências de arte e ativismo midiático. Teve a sua edição brasileira realizada em 2003. 
conceitos, demonstrando que o estilo serve de elo para se analisar a conexão entre os comportamentos individuais e as ideologias dominantes que estão ligadas às diversas formas de dominação na sociedade, com isso demonstrando a fecundidade da teoria feminista para pensar o conjunto dos processos de reprodução e transformação social. Bauman e Briggs (1990), por sua vez, postulam que o contexto a partir do qual devemos interpretar a performance deve ser buscada em sua própria estética, que fornece o enquadramento (as premissas) de sua própria expressão. Nesse sentido, podemos interpretar que a repetição e a criação presentes em cada performance formam um conjunto que corresponde à sua singularidade. Pacheco de Oliveira (2009) afirma que essas premissas orientam as perguntas, ações, expectativas e emoções dos sujeitos, e que as relações entre essas perspectivas e os processos históricos podem ser analisadas com o conceito de "situação histórica". A análise das performances dos participantes da rádio Xibé, distinguindo as formas criativas com que mobilizam os estilos, foi a chave para diferenciar as suas perspectivas e explorar as suas relações com as ideologias.

\section{As histórias de vida dos participantes da rádio Xibé}

A análise das performances poderia ter sido iniciada a partir de qualquer das suas modalidades, mas optou-se pela estratégia de tomar as histórias de vida como indicadoras privilegiadas das premissas a partir das quais interpretar as demais performances de cada sujeito. Embora a performances sejam singulares, elas mobilizam estilos que podem ser comparados, já que correspondem às ideologias. Foi facilitada a produção de um conjunto de histórias de vida que, através da análise formal e da comparação, permitiu a indução de alguns estilos. Estes não são padrões ou regras impostas a coletividades delimitadas, mas tópicas que podem ser mobilizadas criativamente como parte das táticas de produção de cada 
performance. Não só cada sujeito pode inventar inúmeras performances, como cada performance pode combinar ilimitados estilos. Por outro lado, não há como o sujeito se inserir no mundo social sem utilizar e ressignificar os estilos.

Entre os participantes da Xibé, o estilo que apareceu com mais força foi nomeado como "luta por estabilidade e ascensão social". Tem o trabalho como temática central, e foi surpreendente detectar a analogia entre este estilo e a imagem do trabalho presente no conceito de alienação do trabalho de Marx (1987): os sujeitos da pesquisa narram uma vida voltada ao trabalho, mas muito pouco ou nada dizem os seus processo e frutos. O trabalho é apenas o meio para a sobrevivência e a ascensão social do narrador e sua família. Um outro estilo que apareceu foi o "consumista", que desloca o foco da luta para a aquisição de bens industrializados. No entanto, esse estilo apareceu apenas de forma marginal em alguns relatos, ao lado de outros estilos que tinham uma presença mais marcante. Surgiu também o "estilo especialista": a forma de organização da narrativa em que habilidades especializadas ganham força, e que foi utilizada por entrevistados que adquiriram formação universitária. Nestes casos as narrativas expressam uma fruição e identificação maior com o processo e os frutos do trabalho, mas isso ocorre dentro dos limites da especialidade. O "estilo ativista", muito intenso na elaboração da trajetória do pesquisador, coloca a luta social organizando a narrativa. Ele se aproxima do especialista, pois tende a tratar a luta social como uma espécie de especialidade profissional com seus jargões e conhecimentos especializados. O estilo da "liderança comunitária" também se aproxima do especialista por dar grande atenção a profissões especializadas e cargos de liderança, mas com a diferença de que subordina essas atividades ao serviço às comunidades ou povos de origem dos narradores.

Finalmente, apareceu com bastante força o estilo da "produção lúdica da vida", no qual o foco da narrativa são os processos de produção, 
experimentação e criação de coisas e relações na vida dos narradores. Encontramos uma analogia entre as características desse estilo e a imagem do "desejo" de Guattari (2011). O filósofo e psicólogo recusa as teorias que opõem uma ideia de desejo como um "mundo bruto", uma energia ou pulsão indiferenciada, um caos que estaria em oposição à ordem social. Em contraposição a essas concepções, afirma que a maior contribuição de Freud foi a revelação da riqueza simbólica, os "meios de semiotização altamente elaborados" (p. 259) que correspondem ao mundo do inconsciente que se manifesta nos sonhos, na loucura, na infância ou nas sociedades ditas primitivas. Desejo é produção, e diante dele a sociedade não precisa necessariamente impor normas, ordenar, dirigir, empobrecendo a sua criatividade e potência produtiva, embora seja isto o que acontece na sociedade capitalista.

Outra analogia possível desse estilo é com o conceito de "criação" de Castoriadis (1982), que tem como origem a "imaginação radical": a produção incessante de fantasias a partir da qual o sujeito participa da invenção de sua individualidade e do mundo social. Esse fluxo criativo se choca com os demais sujeitos, e é da frustração resultante que nascem as noções de "outro" e de "sujeito". A inserção social do sujeito ocorre através da mediação desses outros sujeitos, e por isso o "mundo público" é o único que pode limitar a imaginação radical. Se originalmente o prazer está ligado ao absoluto que constitui o sujeito em sua origem, a socialização o leva a uma nova forma de desejo, que passa a ser "intenção de modificação no real" (p. 358). É portanto com a mediação do "mundo público", também chamado de "sociedade instituída", que o sujeito produz as "sociedades instituintes" e transforma as coisas e relações. A teoria de Castoriadis mostrou-se especialmente útil para a interpretação das performances da rádio, pois ajudou na compreensão das relações entre criação e estilos, imaginação radical e sociedade instituída. A análise das narrativas revelou que o estilo da produção lúdica da vida era mobilizado com mais intensidade quando se tratava de descrever eventos e 
fases da vida dos interlocutores relacionados com a experiência de participação na rádio e suas atividades. A rádio livre facilita e estimula nos sujeitos o fluxo de suas fantasias e a "intenção de modificação do real".

\section{Uma história polifônica da rádio Xibé}

Além das histórias de vida, foram produzidas narrativas sobre a experiência dos sujeitos na rádio Xibé. Com elas foi tecida uma narrativa polifônica, entrelaçando as suas perspectivas. A linha de costura foi o ponto de vista do/a pesquisador/a, afinal a escrita também é uma performance. $\mathrm{O}$ resultado não foi uma bola de cristal para se olhar o passado, já que as narrativas são parte do processo de invenção de coisas e relações que os sujeitos estão vivendo no presente, mas um diálogo revelador das formas pelas quais as performances da memória fecundam o presente e abrem novas possibilidades para a ação e a imaginação. A metáfora do "rizoma" influenciou o planejamento e o processo de redação desta parte do trabalho, o que já seria suficiente para afastar a história da rádio de concepções que naturalizam a comunicação, entre as quais poderíamos apontar as teorias atualmente dominantes que preconizam a comunicação enquanto transmissão linear de mensagens. Mesmo assim, o resultado da tecedura dos relatos e da sua da análise foi a explosão da metáfora do rizoma, pois esta tornou-se incapaz de dar conta de todas as características da multiplicidade encontrada nas experiências da Xibé.

A metáfora do rizoma facilitou a elaboração de elementos narrativos importantes da tese como a diversidade de origens e desdobramentos da rádio, bem como a complexidade das conexões e de suas rupturas. Porém, não contempla as situações em que a tecedura das narrativas sobre um único evento revela que o mesmo pode comportar simultaneamente diferentes hierarquias com variadas concepções de liderança ou autoridade, a coexistência de fronteiras com amplitudes, graus de abertura e critérios de 
delimitação diversificados, e as composições mais discrepantes, com alguns narradores esquecendo de incluir as mulheres, outros deixado professores de fora, e até mesmo com a elaboração de listas de participantes com quase nenhuma intersecção. Como é possível que, na vivência de um mesmo episódio, uma rádio livre tenha sido experimentada ao mesmo tempo como horizontal para um participante e hierárquico para outro?

Geralmente os pesquisadores conciliam essas discrepâncias estabelecendo arbitrariamente a sua versão da história como sendo a objetiva, e as demais como interpretações subjetivas, como se a diversidade de perspectivas não fosse constitutiva da realidade objetiva e dos seus processos de transformação. Quando se toma a metáfora do rizoma como referência, sente-se como sendo mais real a perspectiva que corresponde melhor à horizontalidade complexa que sugere esta raiz, e as versões que tendem a apresentar graus de hierarquia tendem a ser excluídas da análise. Segundo Spivak (2012), o conceito de desejo de Deleuze e Guattari leva a uma teoria da imanência da subjetividade que inviabiliza a análise dos interesses e das ideologias. A obra de Castoriadis (1982) nos permite conciliar o conceito de desejo com os interesses e as ideologias quando propõem os conceitos de "mundo privado" e "mundo público". É a partir do mundo privado que o sujeito produz a sua imaginação radical e a sociedade instituinte. Mas somente pode fazer isso participando do mundo público, a sociedade instituída. Para inventar novos processos o sujeito precisa manejar os imaginários estabelecidos, e é por isso que as performances não podem ser apenas elaborações desejantes. Por mais libertadora que seja a experiência em uma rádio livre, ela terá necessariamente que integrar estilos da sociedade instituída, ou jamais produzirá a sociedade instituinte.

No caso da rádio Xibé, por mais discrepantes que fossem os relatos em relação às hierarquias mais horizontais ou verticais, às fronteiras e à composição da rádio, praticamente todos os entrevistados mencionaram que nas reuniões e no dia a dia da rádio havia abertura para a fala e a iniciativa de 
todos. Paradoxalmente, podemos concluir que foi justamente o cultivo da comunicação dialógica que permitiu a diversificação das perspectivas e das suas discrepâncias. A dialogicidade fez proliferar na rádio e no seu entorno a apropriação criativa de estilos instituídos, introduzindo nela a reprodução de relações de poder conservadoras mas, justamente por isso, contribuindo para subverter essas relações. Tudo indica que este processo corresponde ao mesmo fenômeno elaborado através do conceito de "coletivização" de Bifo (citado por Colectivo, 1981, p. 56), quando afirma que "a coletivização rompe o domínio do isolamento, e o desejo transforma a cotidianeidade". A diferença é que, para Bifo, o desejo se afirma na recusa da institucionalização, enquanto Castoriadis (1982) e a história polifônica da Xibé apontam que a imaginação radical prolifera através da sociedade instituída. São versões para a mesma experiência:

El diablo ha vuelto sobre la tierra bajo múltiples semblanzas. El diablo es Alicia que es el asalto total al estado de las opresiones; es nuestra sonrisa, nuestra sonrisa, nuestra mente que piensa, el diablo es nuestro cuerpo cada vez más bello e libre y capaz de amar. Hoy el diablo, al que es inútil hacer la corte, tiene miles de caras, muda constantemente de expressión, se desliza por la ciudad, por los barrios, por las fábricas y por las escuelas como un gato salvaje" (Radio Alicia citada por Colectivo, 1981, p. 57-58).

Assim, mais que o rizoma, a metáfora que nos ajuda a analisar a história da Xibé é a do "espectro": cada evento é como um ponto atravessado simultaneamente por diferentes frequências e amplitudes de ondas eletromagnéticas. Se colocarmos um receptor neste ponto, será possível sintonizar diferentes estações. A busca da clareza nos levará a sintonizar uma de cada vez, mas nem por isso deixarão de ocorrer interferências e sintonias. A atenção dispensada por um sujeito a uma perspectiva (geralmente a própria), não impede que ocorram conflitos e diálogos. Achile Mbembe (2013) nos oferece um exemplo de como operacionalizar essa metáfora em análises histórica concretas, em seu estudo sobre a invenção das formas múltiplas de religiosidade nas sociedades africanas pós-coloniais. O autor 
destaca o manejo simultâneo de diferentes registros diante de situações históricas que vão da escala internacional e da longa duração histórica, passando por relações econômicas e de poder nacionais e regionais, chegando até as operações mais triviais da sobrevivência ou dos pequenos interesses da vida cotidiana. Contrapondo-se à teoria de que o cristianismo foi simplesmente imposto no período colonial, e de que precisa ser reinventado a partir das tradições ancestrais para que possa consolidar a sua presença na África, Mbembe traça um quadro muito mais complexo em que os mesmos sujeitos se apropriam dos vários registros existentes (estilos) para as finalidades mais diversas (buscadas em suas performances).

\section{A Xibé e suas redes}

Além das relações locais da rádio Xibé também foram etnografadas as suas conexões em rede e à distância através de movimentos como o Rizoma de Rádios Livres ${ }^{5}$, a rede Indymedia ${ }^{6}$, a Flor da Palavra ${ }^{7}$ e as redes acadêmicas. Entre os militantes conectados à rádio Xibé e que nutriam

5 O Rizoma de Rádios Livres (www.radiolivre.org) surgiu em 2002 e utiliza servidores livres para manter uma lista de e-mail, um site de publicação aberta, sites específicos e serviço de streaming para as rádios livres tecerem a comunicação horizontal.

6 A rede Indymedia (ou Centro de Mídia Independente) nasceu durante os protestos em Seatle (EUA), em 1999. Foi criado um site de publicação aberta de textos, áudios e vídeos por parte dos leitores que estavam participando dos protestos ao redor do mundo, e rapidamente formaram-se centenas de coletivos Indymedia com seus respectivos sites locais e uma rede horizontal unindo os coletivos. O CMI-Brasil (www.midiaindependente.org) começou a ser formado em 2000 unindo coletivos de várias cidades brasileiras, entre eles o CMI-Tefé (http:/ / xibe.radiolivre.org) que começou 2006.

7 A Flor da Palavra (http://flordapalavra.noblogs.org/) foi uma rede de inspiração zapatista que começou em 2006 realizando eventos locais colaborativos para colocar em contato ativistas, grupos populares, pesquisadores e artistas, utilizando tecnologias de comunicação. Em 2009 tentou criar um "Caracol" em um bairro popular de Belém (PA): uma casa voltada a atividades culturais e de organização popular que também poderia hospedar ativistas viajantes. 
simpatia - somente estes aceitaram dar entrevistas -, foi possível classificar aproximadamente duas categorias. Aqueles que mantiveram relações tênues com a rádio, mediada quase que exclusivamente por internet, e os que puderam desenvolver relações mais elaboradas, graças a viagens que propiciaram encontros face a face e a realização de ações conjuntas.

A primeira categoria de militantes tende a projetar (Todorov, 1999) os seus valores e experiências ao selecionar as informações obtidas na internet para construir as suas percepções da rádio, bem como a reproduzir os clichês das ideologias dominantes ao imaginar o seu contexto histórico ou natural. Para esses militantes, a Xibé é um espelho que serve para reforçar suas utopias, pois representa a sua expansão para um contexto exótico (é mais uma rádio livre, mais um CMI, etc, localizado na selva Amazônica). Nesse espelho o militante distante vê a si mesmo, não encontrando um outro sujeito com o qual dialogar, o que revela que a existência de mecanismos de interatividade na internet não é garantia de comunicação.

Por outro lado, há situações em que a atração exercida pelo espelho é suficientemente forte para que ele se torne uma janela. É o caso dos militantes que conheceram a Xibé através de viagens e realizando ações conjuntas. Mary Pratt (1999) demonstra que o olhar dos viajantes é fortemente influenciado por aqueles que o recebem e guiam, tanto na sua trajetória quanto nas percepções. Os encontros face a face e as ações conjuntas propiciaram formas mais consistentes de diálogo, que puderam continuar a se desenvolver mesmo à distância, e percepções mais elaboradas sobre a rádio. As redes também são espectros, cuja multiplicidade se intensifica quando as projeções se tornam mais elaboradas através de viagens e ações conjuntas, quando espelhos se tornam janelas.

\section{Uma situação histórica com ênfase na tecnologia}

Tendo-se como referência o conceito de "situação histórica" de Pacheco de Oliveira (2014), procurou-se repensar a história do rádio, para 
então relacioná-la à etnografia da Xibé e suas redes. Escolhemos tratar dos primeiros anos de invenção do rádio e da internet, cujas afinidades levaram Tim Wu (2012) a formular uma teoria cíclica da história das tecnologias de comunicação. Tanto o rádio como a internet passaram por processos iniciais de invenção popular, sendo transformados em instrumentos para a formação de redes de comunicação dialógica e a organização de movimentos sociais em rede. Depois foram reinventados por Estados e corporações, passando a servir como dispositivos de controle político e exploração econômica, com a mercantilização dos seus usuários. Longe de confirmar a teoria cíclica, este paralelismo sugere algo muito importante: a internet não foi a primeira a servir para experimentos de comunicação autônoma e em rede, e nem há garantias de que continuará propiciando isto.

É mais proveitoso nos apropriarmos do relativismo tecnológico de Pierre Lévy (1993), quando afirma que a informática traz novas possibilidades para a inteligência humana, mas a oralidade, a escrita, o áudio e o visual permanecem vitais. A crítica social e a elaboração de táticas de emancipação precisam levar em conta tanto as novas tecnologias quanto as mais antigas, pois estas também são cotidianamente reinventadas como poderosos dispositivos de dominação e resistência. Além disso, os movimentos de rádio livre e software livre mostram que quanto maior a popularização da ciência e o controle popular sobre a invenção tecnológica, maior a tendência a serem inventadas ferramentas voltadas à práxis dialógica.

\section{Linhas de fuga}

Fabian (1983) atribui à matriz bíblica a visão europeia que pensa a história como uma linha evolutiva, em que o Ocidente apresenta-se como desbravador do futuro, atribuindo aos demais povos diferentes estágios mais ou menos primitivos. Deriva daí o imaginário analisado por Pacheco de Oliveira (2010) sobre a Amazônia como última fronteira, da natureza primal 
e dos povos primitivos. Outro fruto é a evolução pensada enquanto desenvolvimento tecnológico, que está na origem da desvalorização do rádio enquanto tecnologia relevante na atualidade. Assim, a crítica do imaginário evolucionista nos ajuda a valorizar tanto as performances do Médio Solimões quanto as experiências com rádios dialógicas.

Lemos a partir de Spivak (2012), que os estilos são textos que calam os subalternos, a menos que estes se apropriem criativamente deles em suas performances. A única possibilidade de controle sobre a própria expressão é operando recombinações e deslocamentos de sentido que, ao gerar a perplexidade do interlocutor, permite a emergência de significados que não estavam prescritos. De fato, a maioria dos simpatizantes à distância da rádio Xibé relataram alguma surpresa ao tomar conhecimento de uma rádio livre ou centro de mídia independente no interior do Amazonas. A simples combinação entre a tecnologia libertária e um lugar tido como selvagem ajudou a abrir brechas para performances e interações que, no caso de alguns simpatizantes, tornou possível as viagens e ações conjuntas, percepções mais elaboradas e um diálogo efetivo.

Este é também o caso do facilitador desta pesquisa que, provavelmente, viu no zapatismo a mesma combinação do exótico com o tecnológico, construiu uma percepção mais elaborada através da pesquisa de campo etnográfica, e acreditou que processos de apropriação tecnológica voltados para a invenção do diálogo e da descolonização também poderiam ser facilitados na Amazônia. A experiência da Xibé nasceu desta e de muitas outras performances que, entre outros frutos, produziram uma antropologia dialógica da mídia.

\section{REFERÊNCIAS}


ABU-LUGHOD, Lila (1990). The romance of resistance: tracing transformations of power through Bedouin women. American Ethnologist, 17(1), 41-55. Recuperado de: http://www.jstor.org/stable/645251

BAUMAN, Richard; BRIGGS, Charles L. (1990). Poetics and Performance as Critical Perspectives on Language and Social Life. Annual Review of Anthropology, 19, 59-88.

BENJAMIN, Walter (1994). O autor como produtor. In: BENJAMIN, Walter. Obras escolhidas: magia e técnica, arte e política. São Paulo: Brasiliense.

BRECHT, Bertolt (2007). O rádio como aparato de comunicação: discurso sobre a função do rádio. Estudos Avançados, 21(60), 227-232. Recuperado de: http://www.scielo.br/scielo.php?script=sci_arttext\&pid=S0103-

40142007000200018\&lng=pt\&nrm=iso

BUTLER, Judith (2012). Problemas de gênero: feminismo e subversão da identidade. Rio de Janeiro: Civilização Brasileira.

CASTORIADIS, Cornelius (1982). A instituição imaginária da sociedade. Rio de Janeiro: Paz e Terra.

CERTEAU, Michel de (2003). Introdução geral. A Invenção do Cotidiano: Vol.1 Artes de Fazer. Petrópolis: Vozes.

COLECTIVO (1981). Alicia es el diablo: radio libre. Barcelona: Ed. Ricou (Hacer).

DELEUZE, Gilles \& GUATTARI, Félix (1995). Mil platôs: capitalismo e esquizofrenia. Vol. 1. São Paulo: Ed. 34.

ENZENSBERGER, Hans Magnus (2003). Elementos para uma teoria dos meios de comunicação. São Paulo: Conrad.

FABIAN, Johannes (2008). Ethnography as commentary. Durhan/London: Duke University Press.

FABIAN, Johannes (2001). Keep listening: ethnography and reading. In: Anthropology with an attitude. Critical essays. Stanford: Stanford University Press.

FABIAN, Johannes (1983). The time and the other: how anthropology makes its object. New York: Columbia University Press.

FABIAN, Johannes (1996). Time and the work of anthropology: critical essays, 19711991. Amsterdam: Harwood Academic.

FANON, Frantz (1981). "Aquí La Voz de Argelia". In: BASSETS, Lluís (org). De las ondas rojas a las radios libres: textos para la historia de la radio. Barcelona: Gustavo Gili.

FANON, Franzt (2005). Os condenados da terra. Juiz de Fora: Ed. UFJF.

FERGUSON, James (1999). Expectations of modernity: myths and meanings of urban life on the Zambian copperbelt. Berkeley, Los Angeles, London: University of California Press.

GUATTARI, Félix (2011). Micropolítica: cartografias do desejo. Petrópolis: Vozes. 
LÉVY, Pierre (1993). As tecnologias da inteligência: o futuro do pensamento na era da informática. Rio de Janeiro: Ed. 34.

MACHADO, Arlindo, MAGRI, Caio, \& MASAGÃO, Marcelo (1986). Rádios livres: reforma agrária no ar. São Paulo: Brasiliense.

MARX, Karl (1987). O capital: crítica da economia política. Livro 1, volume II. São Paulo: Bertrand Brasil.

MBEMBE, Achille (2013). Africa insubmissa: cristianismo, poder e Estado na sociedade pós-colonial. Portugal/Angola: Ed. Pedagoga/Ed. Mulemba.

OLIVEIRA FILHO, João Pacheco de (2010). Narrativas e imagens sobre povos indígenas e Amazônia: uma perspectiva processual da fronteira. Indiana, 27, 19-46.

OLIVEIRA FILHO, João Pacheco de (2009). O nascimento do Brasil: revisão de um paradigma historiográfico. Anuário Antropológico, 1, 11-40.

OLIVEIRA FILHO, João Pacheco de (2014). Os indígenas na fundação da colônia: uma abordagem crítica. In: Fragoso, João; Gouveia, Fátima (orgs). O Brasil colonial. Rio de Janeiro: Ed. Civilização Brasileira.

OLIVEIRA FILHO, João Pacheco de (2008). Sem a Tutela: uma nova moldura de nação. In: Oliven, Ruben; Ridenti, Marcelo; Brandão, Gildo (orgs). A Constituição de 1988 na vida brasileira. São Paulo: ANPOCS.

PRATT, Mary Louise (1999). Os olhos do império: relatos de viagem e transculturação. Bauro: EDUSC, 1999.

SPIVAK, Gayatri Chakravorty (2012). Pode o subalterno falar? Belo Horizonte: Ed. UFMG.

TODOROV, Tzvetan. A conquista da América: a questão do outro. São Paulo: Martins Fontes.

TRAVANCAS, Isabel \& FARIAS, Patrícia. Antropologia e comunicação. Rio de Janeiro: Garamond/FAPERJ.

WU, Tim (2012). Impérios da comunicação: do telefone à internet, da AT\&T ao Google. Rio de Janeiro: Zahar. 